\title{
服务产业结构转型背景下新能源汽车产业集群的创新型应用人才 培养研究
}

\author{
梁贵贞 \\ 广西培贤国际职业学院 \\ DOI:10.32629/ej.v3i1.358
}

\begin{abstract}
[摘 要] 在国家现代产业体系不断完善的背景下,促进了产业结构全面转型,汽车产业结构也出现改变。现阶段,各地政府部门全面开发新型汽 车、零部件等,所以培养大批量服务产业结构转型背景下新能源汽车产业集群的创新型应用人才,是当前高校汽车类专业重点关注的内容。本文 就新能源汽车专业人才需求分析, 从提升专业课程教师实力、加强校企合作、促进教材建设等多个方面, 重点探究创新型新能源汽车应用型人才 培养策略,具体如下。
\end{abstract}

[关键词] 服务产业结构转型; 新能源汽车; 产业集群; 广西；应用型人才；培养

在能源不断短缺的环境下, 新能源汽车成为了汽车行业发展的重要趋 势, 也是各个汽车生产产业重点探究的方向。广西根据我国新能源汽车产 业发展, 全面倡导汽车工业改革升级, 当前已经成为一个新型的汽车产业 群体, 以柳州、南宁等汽车产业企业为核心, 创建一个新能源汽车产业基 地。与此同时, 广西新能源汽车产业发展离不开人才支撑, 这就需要从新能 源汽车的角度入手, 优化汽车人才教育, 培养创新型应用人才, 助力广西自 治区的新能源汽车产业发展。

\section{1 新能源汽车专业人才需求分析}

在新能源汽车产业中, 主要划分为两部分, 一个是新能源汽车生产产 业, 另一个是新能源汽车应用产业。所以, 在新能源汽车专业发展中, 工作 范畴包含了新能源汽车开发、新能源汽车检测、新能源汽车维修等。与此 同时, 新能源汽车组成、技术和传统汽车之间有着明显差异, 对专业人员综 合素养需求也各不相同。现阶段, 新能源汽车专业培养过程中, 应该保证其 具有以下几点素养。首先, 新能源汽车专业人员应该掌握专业电子技术, 掌握现代化节能材料, 并且对信息技术操作有所了解。在新能源汽车开发 过程中, 包含部分电池管理等装置和设备, 所以汽车专业人员应该掌握该 方面内容, 以更好迎合岗位工作要求 ${ }^{[1]}$ 。

其次, 无论是传统汽车, 还是新能源汽车在应用中或多或少会面临一 些问题, 所以, 汽车维修管理是非常重要的。针对新能源汽车维修专业技术 人员, 不但要掌握专业的汽车维修技术, 同时还要对新能源汽车维修有一 定了解, 具有新能源汽车维修资格证, 结合新能源汽车维修要求, 学习更多 电工等方面技术。新能源汽车和传统汽车比较得知, 对维修人员技术水平 有着更要要求, 所以新能源汽车专业人员不但要掌握丰富理论知识, 还好 具备较强实践操作能力。

最后, 新能源汽车在结构设计和动力原理上存在明显差异, 所以在作 业形式上也会发生诸多改变。从目前情况来说, 新能源汽车中涉及了诸多 现代化技术, 具备一定技术性和专业性, 使得新能源汽车维护管理技术要 求比较严格 ${ }^{[2]}$ 。所以, 在对新能源汽车专业人才培养中, 不但要保证其掌握 专业知识, 同时也具有良好发展能力, 让其可以迎合时代发展而发展。

\section{2 创新型新能源汽车应用型人才培养策略}

在新能源汽车产业专业人才培养过程中, 培养重要机构在于职业院校。 在进行新能源汽车人才培养中, 应该把市场发展需求当作核心, 把培养学生 专业水平和职业技能当作目标, 通过专业课程设计、编制教学材料、教学 模式选择等, 引导创新型新能源汽车应用型人才培养目标顺利完成。

2. 1 结合市场发展, 专业课程教师要不断提升实力
在新能源汽车中, 包含大量现代化技术, 同时技术应用范畴的扩充, 涉 及信息技术、电工电子技术等内容。所以, 在新能源汽车产业专业人员培 训过程中, 应该强化培训力度, 并结合时代发展情况, 确保从事新能源汽车 产业教育的工作人员满足新能源汽车产业专业教育要求。在此过程中, 不 但需要新能源汽车产业教师提高自身综合能力, 并且还要掌握更多新能源 汽车产业知识, 根据新能源汽车产业发展方向, 积累更多专业知识量, 通过 实际调查, 对现代化新能源汽车产业生产形式有深入了解, 掌握企业岗位 工作标准, 给新能源汽车产业专业人才培育打下扎实基础 ${ }^{[3]}$ 。除此之外, 在 实际新能源汽车产业教学过程中, 应该把现代化技术引入其中, 通过丰富 教学内容, 转变教学格局, 让学生了解更多专业知识的同时, 提高学生专业 素养, 引导新能源汽车产业教学目标顺利实现。

\section{2加强校企深度合作}

通过采用校企合作模式, 不但能够打破传统教学带来的约束, 同时也 能有效处理之前新能源汽车产业专业人才培育中各个问题。所以, 在新形 势环境下, 无论是技工学校, 还是企业, 在培养新能源汽车产业专业人才过 程中将会面临诸多考验。通过建立长久合作关系, 构建完善的人才培育体 系, 明确新能源汽车产业专业教育目标, 实现校企资源共享, 不但能够让学 校学生对今后从事的工作岗位有深入的了解, 同时也能给企业培养更多专 业性人才。在校企合作模式作用下, 能够将传统教学模式进行深入改革, 适当扩充教学范畴, 获取更多信息资源, 给校企合作教育体系改革提供数 据参考 ${ }^{[4]}$ 。与此同时, 学校通过和新能源汽车生产企业一同建立人才培养 体系, 一同完善人才培养目标和教学制度, 共享教学资源, 在深化校企人才 培养内涵的同时, 便于学生综合水平的提高, 实现学生专业素养的培养。

2.3 依据产业发展需求, 加快教材建设

教学材料是教学活动有序进行的依据, 更是教育活动顺利开展的保 障。在新能源汽车产业专业教学中, 也需要得到教学材料的支持。随着新 能源汽车技术水平的提升, 提高新能源汽车专业教学材料有效性和专业性, 编制新能源汽车技术教材是非常重要的。所以, 学校应该结合新能源汽车 发展情况和新能源汽车专业人才培养要求, 对现有教学内容进行改革, 同 时在教学内容编排上秉持由简到繁的标准, 让教学内容日渐深入, 让教学 材料可以满足新能源汽车专业人才教育要求。与此同时, 教学材料应该满 足一体化教学标准, 符合新能源汽车专业人才培养要求, 不但要给学生讲 解更多理论知识, 同时需要给学生提供实践机会, 让学生在实践中得到锻 炼, 引导学生综合发展。

2. 4 依据人才培养规律, 构建专业课程体系 


\section{民政档案管理中提高低保档案管理效用探析}

郑婷

吉林省洮南市社会事业救助中心

DOI:10.32629/ej.v3i1.360

[摘 要] 目前阶段,民政档案管理工作的重要性逐渐突显出来,为民政工作的贯彻落实提供了必要帮助。其中,低保档案管理是民政档案管理的 重点内容。基于此,文章将民政档案管理中的低保档案管理作为主要研究对象,重点阐述具体的管理策略,以提高低保档案管理的效用,希望有所 帮助。

[关键词] 民政档案；低保档案；管理效用；提升路径

低保档案为民政档案管理工作的重点,在不断加强档案管理力度的基 础上, 可更好地提高档案管理水平。在理论层面深入探究低保档案管理工 作, 可为低保档案管理工作的开展提供有价值的参考依据。

\section{1 低保档案基本特点阐释}

现阶段, 社会经济发展速度明显加快, 城乡低保档案管理的特点与变 化也逐渐突显出来, 对于低保档案管理工作也提出了全新要求。其中, 低保 档案的基本特点集中体现在以下几个方面, 主要包括多面性、动态性、双 向性三个方面:

\section{1 多面性}

伴随国内社保体系的健全与完善, 使更多的困难群众获得必要福利。 然而, 在审批最低生活保障待遇的过程中, 申请具有多面性特征 ${ }^{[1]}$ 。审查低 保期间, 会涉及诸多部门, 要求低保申请人员向居委会亦或是村委会发送 申请, 并交由上一级街道办事处以及民政部门负责复核, 最终需要县级以 上民政部门审批并决定。所以说, 在申请低保的时候, 多面性特征明显, 需 要经过相对严格的审批程序。

\section{2 动态性}

实施最低生活保障管理期间, 执行程序的动态性也较为明显。特别是 低保档案管理期间, 管理的手段也伴随经济变化而发生改变。基于市场经 济的多元化发展阶段, 低保人员的数量随之改变 ${ }^{[2]}$ 。为不断增强最低生活 保障监督工作, 管理工作人员要系统检查并维护低保户, 结合家庭经济状 况, 采取必要的调整措施, 并参考低保范围改变情况, 深入分析低保户对象, 不断增强低保档案管理工作的有效性以及针对性。

1.3双向性

新能源汽车中涉及的内容比较广泛, 所以需要从业人员掌握更多专业 知识。为了更好满足新能源汽车行业发展要求, 需要对专业课程重新构建。 在新能源汽车专业课程体系建设中, 应该把学生职业素养发展当作核心, 根据岗位标准, 完善专业课程体系。并且, 在课程体系建设中, 应该对新能 源汽车岗位需求进行综合分析, 明确新能源汽车对各个岗位工作要求。并 且, 根据学生学习特点和需求, 对岗位需求能力综合划分, 把理论知识和教 学内容充分结合, 让课程体系构建更为全面, 引导学生学习更多相关知识, 提升学生职业素养和水平。

\section{3 结束语}

总而言之, 随着我国能源不断匮乏, 为了实现社会稳定发展, 各个领域 均加大新能源开发。新能源汽车成为了现阶段汽车行业重点发展方向。为 了更好满足汽车行业发展要求, 各个学校均在内部设有汽车专业, 对新能 源汽车专业人才进行全面教育, 给社会培养更多专业水平高、综合素养强 的汽车专业人才。各个院校可以结合新能源汽车产业发展, 明确新能源汽
近年来,计算机信息技术水平不断提高, 国内民政部门开始针对最 低生活保障工作实施系统管理, 在与其他社会保障部门合作的基础上, 促进了信息化的有效拓展。现阶段,档案管理信息化建设的服务器以及 信息数据已经被合理安排至各省市重要区域,通过对网络技术的合理运 用, 即可向基层民政管理单位安排, 为后期基层低保档案管理工作的开 展奠定了坚实基础。综合考虑管理现状, 基层管理工作人员需要综合考 虑自身状况, 尽快收集、管理并复核低保户的基础资料, 进一步优化工作 质量与效率 ${ }^{[3]}$ 。但仍需注意的是, 即便信息技术发展速度较快, 始终要高 度重视纸质档案管理工作, 促进纸质档案向电子化的有效转变, 突出管 理的双向性特征。

\section{2 民政档案管理中低保档案管理基本原则}

积极开展低保档案管理工作的过程中, 必须要综合考虑实际情况, 遵 循具体原则, 进一步提高民政档案管理工作的效用。在对低保档案管理期 间, 应参考分级管理基本原则, 分别管理县级档案、乡镇档案与村组档案, 重点管理专业文件材料, 保证各级别的作用得以充分发挥, 进而优化低保 档案管理工作质量。另外, 在民政档案管理期间, 低保档案管理工作的开展 需践行动态化管理原则, 在审批低保对象材料以后, 要积极落实动态管理 措施, 与实际情况相结合并做出调整策略。除此之外, 双规原则也必须得到 重视, 为低保档案管理水平的提升奠定坚实基础。

\section{3 民政档案管理中低保档案管理问题}

近年来, 民政档案管理工作取得了理想的发展成就, 但其中的低保档 案管理仍存在一定的缺陷并有待完善。

一方面, 档案资料收集有待完善。收集档案是低保档案管理工作开展 车专业教学水平的同时, 让从事该专业的学生可以快速适应工作岗位, 在 增强学生综合能力的同时, 更好满足汽车行业发展需求。

\section{[参考文献]}

[1]高欣,李蓉.新时代新能源汽车专业建设探究 [J].汽车实用技 术,2019(22):3-51.

[2]劳黄平.新能源汽车技术发展路线的探讨 [J].内燃机与配 件,2019(22):221-222.

[3]李姻娟.新时期如何培养新能源汽车维修人才[J].课程教育研 究,2019(48):34.

[4]侯晓利,隋礼辉,夏继伟.新能源汽车专业人才培养方案的创新性研 究[J].教育教学论坛,2019(48):123-124. 